http://jmscr.igmpublication.org/home/ ISSN (e)-2347-176x ISSN (p) 2455-0450

crossref DOI: https://dx.doi.org/10.18535/jmscr/v8i3.61

\title{
Morphology and Morphomertry of Sternal Foramen and Variations in Xiphoid Process in Human dry Sternum in Jammu Region
}

\author{
Author \\ Dr Rekha \\ Post MD Demonstrator, Department of Anatomy, Govt. Medical College Jammu \\ *Corresponding Author \\ Dr Rekha \\ Post MD Demonstrator Department of Anatomy Govt. Medical College Jammu. J\&K (India)
}

\begin{abstract}
Sternal foramen (SF) represents a congenital anatomic defect, occurring as a result of an impaired and incomplete ossification centre fusion. This study was conducted in Department of Anatomy, Government Medical College, Jammu on 25 adult human dry sternum. Our aim is to observe the presence of sternal foramen, the location, number, shape and size of the foramen and variations in shapes of xiphoid processes. In our study 12\% of sternum had sternal foramen and 6 bones had variations in xipoid part. The xiphoid process is the smallest part of the sternum and most variable in shape present in the epigastrium and is clinically important because it is related with heart, liver, lungs and with stomach. Awareness of sternal variations such as sternal foramen is important for Radiologists and Forensic experts for proper interpretation. Sound knowledge about this variant is important in bone marrow aspiration and acupuncture practice to avoid complications.
\end{abstract}

Keywords: Sternum, Sternal foramen, xiphoid process.

\section{Introduction}

The sternum or breastbone is a long vertical flat axial bone located in the midline of front of the chest forming the anterior part of thoracic cage and thus helps to protect vital organs like heart, lungs and major blood vessels. It is flat bone consisting of spongy marrow. The average length of sternum in the adult is about $17 \mathrm{~cm}$ and consists of three parts from above downwards manubrium sterni, body and a pointed xiphoid process. The manubrium is upper broadest and thickest part which joins the body and forms projecting sternal angle or angle of Louis. The body or Gladiolus is the longest part of the sternum..It is formed by union of four sternebrae. The xiphoid process is a thin sword-shaped process and is the smallest and most variable part of the sternum and may be bifid or perforated showing great amplitude of variations. It articulates above with the body of sternum forming xiphisternal joint and laterally with the inferior portion of $7^{\text {th }}$ costal cartilage ${ }^{[1,2,3]}$. its caudal end is related to the central tendon of the diaphragm and inferior border of the heart. Sternum is embryologically formed by the fusion of sternal ossification centres located in the manubrium, as well as in the mesosternum. Sternal foramen (SF) represents a congenital anatomic defect, occurring as a result of an impaired and incomplete ossification centre fusion. The first description of the SF was conducted by Massa in 
17th century. Also, Eustachius belongs to the group of pioneers, who noticed and described this important anatomic variation ${ }^{[4]}$. Sternal foramina are openings or defects frequently manifesting at the inferior parts of the sternum which may leads to fatal cardiac tamponade and can be both a clinical, radiological and medico-legal challenge when encountered. Awareness of this important anatomic variation is fundamental for clinicians and autopsy pathologists, in order to avoid severe fatal complications and evaluate the exact cause of death, respectively. ${ }^{(5)}$ Awareness of a sternal foramen is important in acupuncture practice and sternal marrow aspiration because of the major risks of heart damage. ${ }^{(1,2)}$ Patients with enlarged xiphoid process with xiphisternal angle of less than 160 degrees are more likely to develop xiphoidalgia; these variations and abnormalities of sternum may affect clinical procedures and diagnosis such as intercostal nerve blocks, interpretation of sternal images and evaluation of chest trauma, among other thoracic procedures and diagnostics, accordingly the current study was aimed to study presence of sternal foramen and variations in xiphoid process of dry human sternum bones. The morphometric study of the sternal foramen is important in Acupuncture practice and sternal marrow aspiration to prevent the damage of vital structures like pericardium and heart. Knowledge of the existence of such anatomic variants is important to avoid complications and misdiagnosis as an osteolytic process. ${ }^{(6,7,8)}$

\section{Methods}

This study was carried out on 25 human dry sternum bones irrespective of age and sex at Govt Medical College Jammu. All the sternum bones were macroscopically inspected for presence or absence of sternal foramen and its location, size, number. and shape. Variations in shapes of xiphoid process of human dry sternum bones were also noted. Photographs of the sternum with sternal foramen and variations in shapes of xiphoid process were taken for proper documentation.

\section{Results}

Out of 25 human dry sternum bones the following variations were noted-

Complete sternal foramina in the body of the sternum were noted in 3 bones (12\%), with an average vertical diameter of $5.6 \mathrm{~mm}$ and transverse diameter of $7 \mathrm{~mm}$ (The highest vertical diameter of $10 \mathrm{~mm}$ and transverse diameter of $10 \mathrm{~mm}$ was noted)[Figure 1 ] In this study sternal foramen was noted in 3 bones.

\section{Site of Sternal foramen}

The sternal foramen were on the body of the sternum, in 2 bones sternal foramen was present at the junction of $3 \mathrm{rd}$ and $4^{\text {th }}$ sternal segment and in another bone it was present at the 4th sternal segment.

\section{Shape of sternal foramen}

One of Sternal foramen was transversely oval (Fig1 A).

Another one showed rectangle shaped foramen (Fig 1 B).

Third sternum had small rounded foramen (Fig 1 C)

\section{Size of sternal foramen}

The size of sternal foramen is measured with Vernier caliper and recorded.

Sternum shown in Fig 1A had sternal foramen $5 \mathrm{mmX} 10 \mathrm{~mm}$

sternum shown in Fig 1B had sternal foramen 10X $9 \mathrm{~mm}$

Sternum shown in Fig 1C had sternal foramen $2 \mathrm{mmX} 2 \mathrm{~mm}$ 


\section{JMSCR Vol||08||Issue||03||Page 350-356||March}

Table-1 Showing number of bones having Sternal foramen

\begin{tabular}{|l|c|c|}
\hline Total no. Sternum & No. of Bones with Sternal foramen & Percentage \\
\hline 25 & 03 & 12 \\
\hline
\end{tabular}

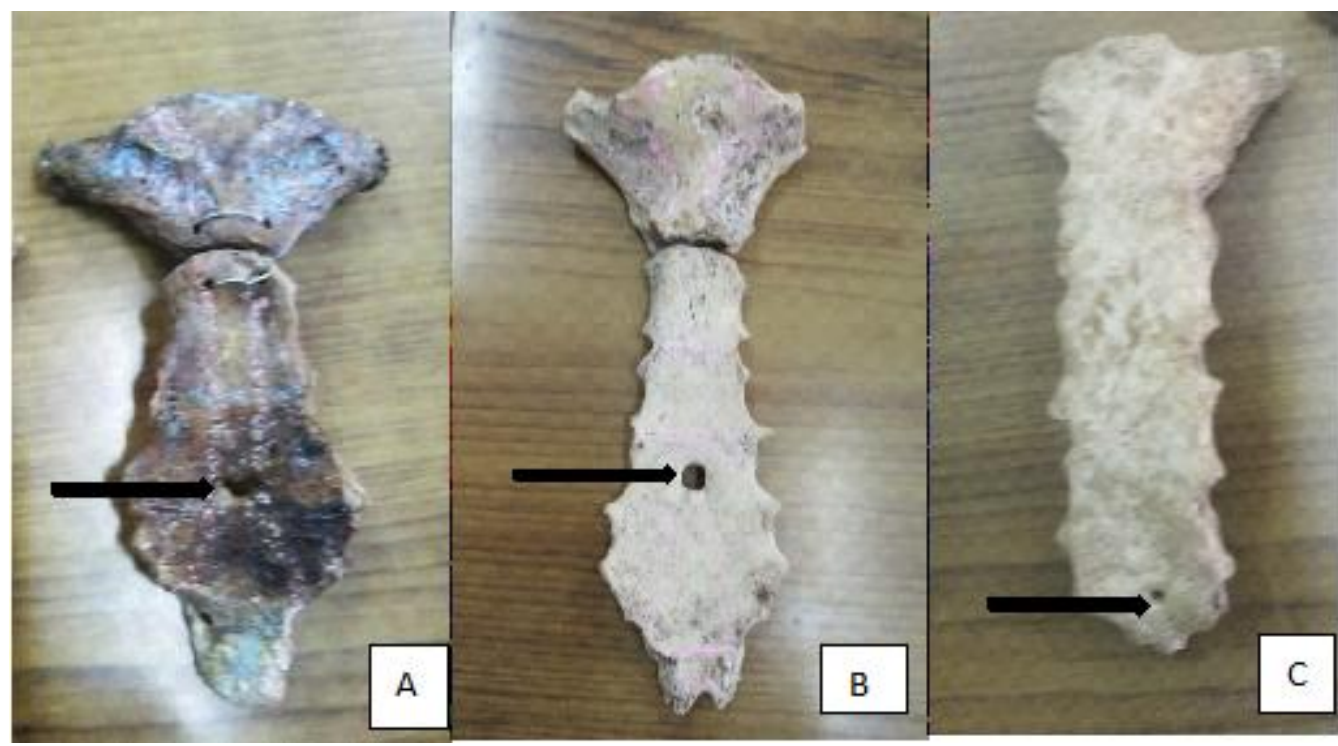

FIG -1 Complete Sternal foramen in A, B and C Shown by arrows

Table-2 Showing location of Sternal Foramen

\begin{tabular}{|l|c|c|}
\hline Site of sternal foramen & No. of bones & Percentage \\
\hline Junction of $3^{\text {rd }}$ and $4^{\text {th }}$ sternal segment & $\mathbf{2}$ & $\mathbf{8}$ \\
$4^{\text {th }}$ sternal segment & $\mathbf{1}$ & $\mathbf{4}$ \\
\hline
\end{tabular}

Table- 3 Showing shapes of sternal foramen

\begin{tabular}{|l|c|c|}
\hline Shape of sternal foramen & No. of bones & Percentage \\
\hline Oval & $\mathbf{1}$ & $\mathbf{4}$ \\
Rectangular & $\mathbf{1}$ & $\mathbf{4}$ \\
Round & $\mathbf{1}$ & $\mathbf{4}$ \\
\hline
\end{tabular}

Table-4 Showing size of sternal foramen

\begin{tabular}{|l|c|c|}
\hline Bone & Transverse diameter & Vertical diamerter \\
\hline Sternum in figure 1A & $10 \mathrm{~mm}$ & $5 \mathrm{~mm}$ \\
Sternum in figure 1B & $9 \mathrm{~mm}$ & $10 \mathrm{~mm}$ \\
Sternum in figure 1B & $2 \mathrm{~mm}$ & $2 \mathrm{~mm}$ \\
\hline
\end{tabular}

\section{Variations in Xiphoid process}

Out of total 25 dry human sternum bones studied, 6 bones showed variable shapes of xiphoid processes. 2 bones showed complete sternal foramen along with variation in xiphoid process [Figure $2 \mathrm{~A} \& \mathrm{C}$ ] and 4 of the bones had variation in the xiphoid process with no sternal foramen..

Following are the observations noted -

- Bifid xiphoid process at the terminal end with complete sternal foramen was seen in 1 bone[Figure2A]
- Unusual Long xiphoid process with sharp bifid end was seen in 1 bone [Figure 2B]

- long xiphoid process with complete sternal foramina was noted in 1 bone [Figure $2 \mathrm{C}$ ]

- Sharp Bifid xiphoid process was seen in 1 bone [Figure 3D]

- One of the bones showed trifurcated xiphoid process [Figure 3E]

- Long Xiphoid process without sternal foramen was seen in one bone [Figure 3F] 


\section{JMSCR VoI||08||Issue ||03||Page 350-356||March}

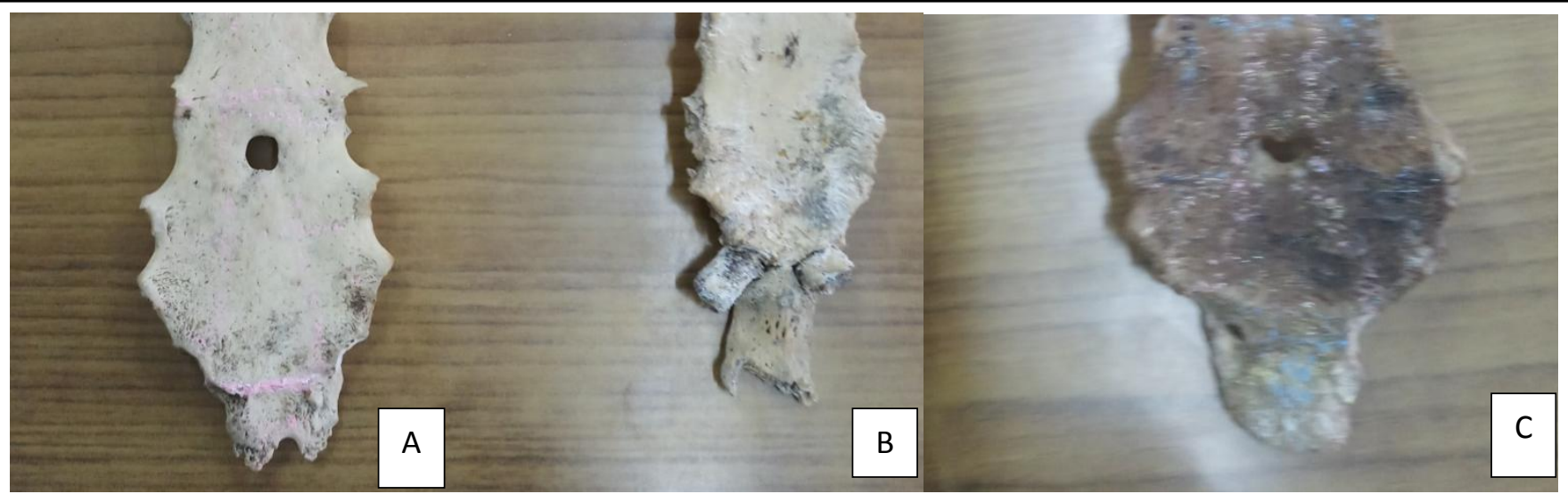

Fig -2 Showing variations in shapes of xiphoid processes. A Showing Bifid xiphoid process B Showing long xiphoid process with sharp bifid end .C Showing long xiphoid process with rounded end.
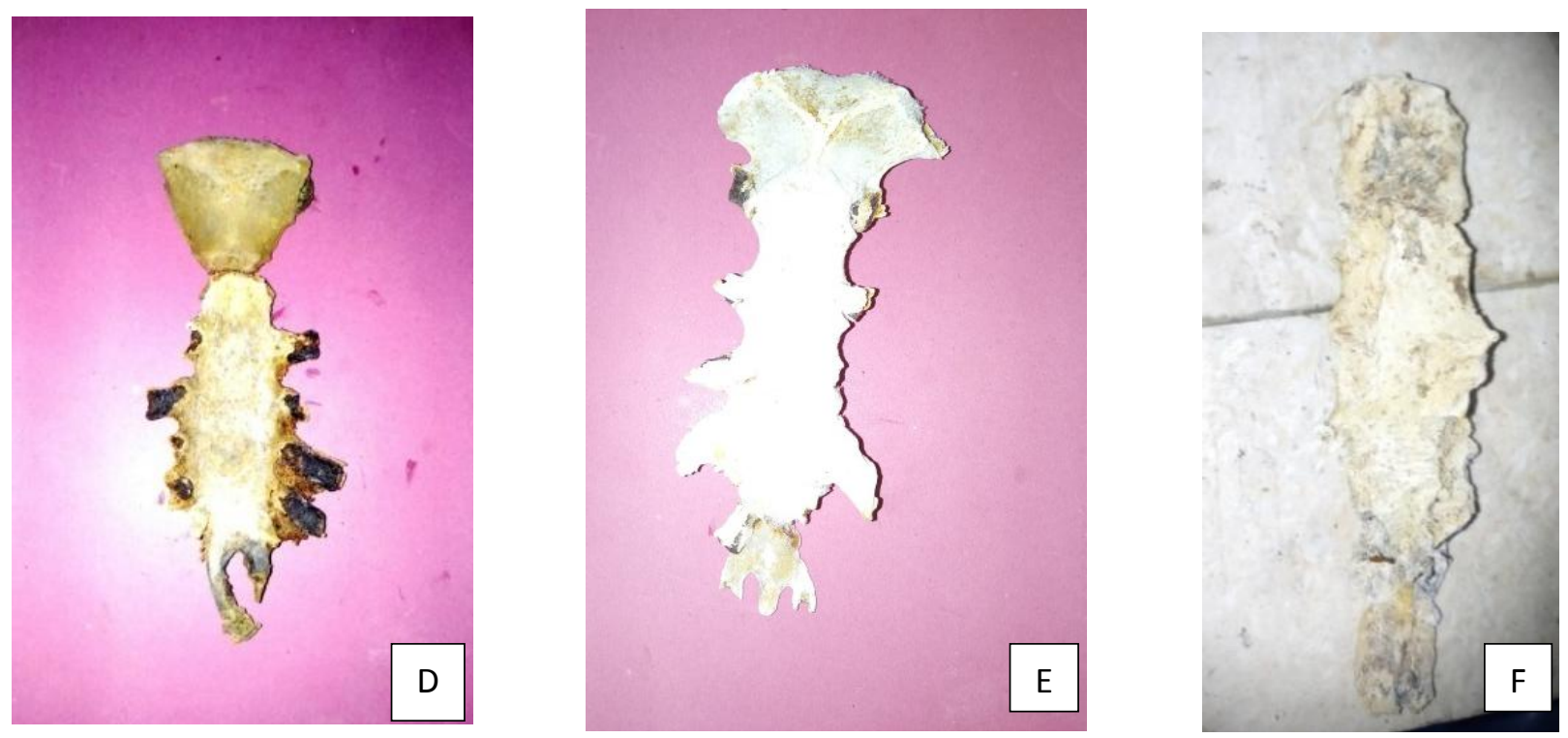

Fig -3 Showing variable shapes of xiphoid processes

\section{Discussion}

The sternal foramen (SF) constitutes a specific anatomic defect in sternum, indicating an impaired fusion of ossification segments. The embryologic development of the sternum originally consists of two cartilaginous bars, situated one on either side of the median plane and connected with the cartilages of the upper nine ribs of its own side. These two bars fuse with each other along the middle line to form the cartilaginous sternum which is ossified from six centers. One ossification centre for manubrium, four ossification centres for body of the sternum and one for xiphoid process. The ossification centres for upper part developed earlier and subsequently proceed further downwards. Timing of appearance of ossification centres as follows, 6th IUL appear in the manubrium and 1st piece of body of sternum, 7th IUL second and third piece of body of the sternum, in the first year fourth piece of sternum and for xiphoid process ossification center developed between 5 th to 18 th year ${ }^{(9-13)}$.Failure of fusion of the sterna brae leads to development of sternal foramen. This is most commonly occurring in between the 3rd and 4th sternabrae.

Sternal foramina may be of various dimensions. Stark et al reported $4.3 \%$ incidence of sternal foramen on chest CT, $6.7 \%$ in autopsy cases by Cooper, $6.6 \%$ by Moore et al, $5.1 \%$ in Turkish population by Aktan et al, and $16.6 \%$ in cadavers and dry bones by Babinski et al ${ }^{(14-18)}$ Where as in our study we observed $12 \%$ of sternal foramen in the body of sternum. Jitender Kumar et al reported 
sternal foramen with a length of $18.75 \mathrm{~mm}$ and width $12.50 \mathrm{~mm}^{(23)}$. Where as in our study we observed with an average vertical diameter of $5.6 \mathrm{~mm}$ and transverse diameter of $7 \mathrm{~mm}$ (The highest vertical diameter $10 \mathrm{~mm}$ and transverse diameter of $10 \mathrm{~mm}$ was noted). The sternal foramen can lead to misinterpretation and wrong conclusions as bullet injuries which have serious consequences; they could also be confused with ante-mortem traumatic injuries. Posterior surface of lower two pieces of sternum is related to the pericardium the defect in the body of sternum leaves only the skin separating heart from the surface at the site of foramen, thus any penetrating injury would easily cause more severe damage to the heart than would normally be. Damage to the heart and great vessels through the foramina has occurred in transthoracic and abdominal penetration; seven cases of injuries to the heart and the pericardium have been described in scientific literature ${ }^{(9,10,19,20)}$ Among which three were fatal, two of the fatal cases were caused by lack of awareness of the sternal foramen. ${ }^{(11,12)}$ Knowledge of the existence of such anatomical variants is important to the clinician because infiltration, biopsy or acupuncture of this area may lead to fatal cardiac complications. With the increasing road traffic crash-related trauma, it is important for clinicians to be aware and suspicious of the aforementioned variations and anomalies so as to avoid misdiagnosis as fracture or traumatic fissure.

The xiphoid process is the smallest part of the sternum present in the epigastrium and it is continuous with the lower end of the body at xiphisternal joint. It is cartilaginous in youth but more or less ossifies in adults and may transform to a synostosis with the sternal body by the age of 40th year or remain unchanged even in old age. The xiphoid process gives origin to the diaphragm muscle an insertion for the rectus abdominis and transverse abdominis muscles. The xiphoid process may be triangular with a pointed caudal end, broad and flat, bifid, perforated, deflected to one side or curved anteriorly. The inferior end lies at the level of T10 vertebrae. Unusual Long xiphoid process with a sharp bifid end noted in this study may damage the liver. Xiphoid process is clinically important because this is also site of the infrasternal or subcostal angle formed by the right and left costal margins. It also serves as a landmark for inferior border of the heart, superior limit of the liver and the central tendon of diaphragm. Shivakumar $\mathrm{G}$ et al reported the incidence $7 \%$ had elongated xiphoid process and that of bifid xiphoid process was $4.6 \%$ in dry sterni $^{(21)}$ In cadaver study by El-Busaid et al reported the incidence of xiphoid foramen was $2.5 \%$ and bifid xiphoid process was $12.5 \%{ }^{(22)}$ Where as in our study we noted the incidence of bifid xiphoid process was $12 \%$ (3 bones) and longer xiphoid process was $8 \%$ (2 bones).long xiphoid process noted in our study may decrease the xiphisternal angle and more likely to develop xiphoidalgia or may be mistaken for an epigastric mass. Moreover, unusual longer xiphoid process with sharp bifid ends noted in this study may misguide during cardiopulmonary resuscitation for a bony landmark to determine the location for administering chest compressions or may be mistaken for fractures in radiological examination. Such morphological variants of xiphoid process are important for cardiothoracic surgeons, physicians and radiologists to avoid misdiagnosis.

\section{Conclusions}

Sternal foramen and variations in xiphoid process are common anomalies and profound knowledge of their existence found in this study is essential especially for bone marrow sampling, radiology, forensic medicine post-mortem reporting and acupuncture practice to avoid complications during various surgical procedures.

\section{References}

1. Duraikannu C, Noronha OV, Sundarrajan P. MDCT evaluation of sternal variations: Pictorial essay. Indian J Radiol Imaging. 2016; 26(2): 185-194, doi: 10.4103/0971- 
3026.184407, indexed in Pubmed: 27413263.

2. Uzun C, Atman ED, Ustuner E, et al. Surface anatomy and anatomical planes in the adult turkish population. Clin Anat. 2016; 29(2): 183-190, doi: 10.1002/ca.22634, indexed in Pubmed: 26403267.

3. Xie YZ, Wang BJ, Yun JS, et al. Morphology of the human xiphoid process: dissection and radiography of cadavers and MDCT of patients. Surg Radiol Anat. 2014; 36(3): 209-217, doi: 10.1007/s00276-013-1163-8, indexed in Pubmed: 23839070

4. Ashley GT.The relationship between the pattern of ossification and the definitive shape of the mesosternum in man. J Anat. 1956; 90(1): 87-105, indexed in Pubmed: 13295154.

5. N. Gkantsinikoudis. Morphological approach of the sternal foramen: an anatomic study and a short review of the literature Folia Morphol 2017; 76( 3): 484-490

6. Kumarasamy SA, Agrawal R. A large sternal foramen. Int J Anat Var. 2011: 4: 195-6.

7. Surgical Anatomy - Skandalakis. 2004.

8. Yekeler E, Tunaci M, Tunaci A, et al. Frequency of sternal variations and anomalies evaluated by MDCT. AJR. 2006;186:956-60.

9. Cheng TO. Pericardial effusion from selfinserted needle in the heart. Eur Heart J. 1991;12(8):958.

10. Hasegawa J, Noguchi N, Yamasaki J, Kotake H, Mashiba $\mathrm{H}$, Sasaki $\mathrm{S}$, et al. Delayed cardiac tamponade and hemothorax induced by an acupuncture needle. Cardiol. 1991;78(1):58-63.

11. Halvorsen TB, Anda SS, Naess AB, Levang OW. Fatal cardiac tamponade after acupuncture through congenital sternal foramen. Lancet. 1995;345(8958):1175.
12. Schiff AF. A fatality due to acupuncture. Med Times. 1965;93:630-1.

13. Shivakumar GL, Deepa G, Kadlimatti HS. Variations in the human sterna. J Evolution Med Dent Sci. 2013;2(2):99104.

14. Stark P. Midline sternal foramen: CT demonstration; J Comput Assist Tomogr. 1985;9:489-90.

15. Cooper PD, Stewart JH, McCormick WF. Development and morphology of the sternal foramen. Am J Forensic Med Pathol. 1988;9(4):342-47.

16. Moore MK, Stewart JH, McCormick WF. Anomalies of the human chest plate area. Radiographic findings in a large autopsy population. Am J Forensic Med Pathol. 1988; 9(4): 348-354, indexed in Pubmed: 3239557.

17. Aktan ZA, Savas R.. Anatomic and HRCT demonstration of midline sternal foramina. Turkish J Med Sci. 1998;28(5):511-4.

18. Babinski MA, Rafael FA, Steil AD, Sousa-Rodrigues CF, Sgrott EA, de Paula $\mathrm{RC}$, et al. High prevalence of sternal foramen: quantitative, anatomical analysis and its clinical implications in acupuncture practice. Int. J Morphol. 2012;30(3):104249.

19. Peuker ET, White A, Ernst E, Pera F, Filler TJ. Traumatic complications of acupuncture: therapists need to know human anatomy. Archives Family Med. 1999;8(6):553.

20. Nieda S, Abe T, Kuribayashi R, Sato M, Abe S. Case of a cardiac injury resulting from acupuncture. Kyobu Geka. 1973;26 (12): 881-3.

21. Shivakumar GL, Deepa G, Kadlimatti HS. Variations in the human sterna. J Evolution Med Dent Sci. 2013;2(2):99104.

22. El- Busaid H, Kaisha W, Hassanali J, Hassan S, Ogeng'o J, Mandela P. Sternal foramina and variant xiphoid morphology 
in a Kenyan population. Folia Morphol (Warsz). 2012;71(1):19-22.

23. Jakhar JK, Dagar T, Dhattarwal SK, Pal V. The sternal foramen: the possible forensic misinterpretation of an anatomic abnormality. J IndAcad For Med. 2015;37(3):315-6. 